\title{
Retornos, contornos e desvios: a Educação Física na construção curricular dos anos finais do ensino fundamental em uma escola estadual do Rio Grande do Sul
}

\author{
Natacha da Silva Tavares? \\ Elisandro Schultz Wittizorecki
}

\section{RESUMO}

Este texto é fruto de uma dissertação e busca comunicar os achados referentes aos seguintes objetivos específicos: a) compreender que saberes integram a Educação Física (EFI) nos anos finais do ensino fundamental e que lugares ela ocupa na construção curricular; b) compreender as tensões envolvidas no processo de construção curricular da escola e da EFI. A construção curricular da escola e da EFI é constituída por movimentos de retorno, contorno e desvio. Os saberes que integram essa construção são de duas ordens, de formação pessoal e de formação acadêmica, e são desenvolvidos através de práticas tradicionais/reprodutoras, mas também através de práticas que rompem essa lógica. Essa presença concomitante de diferentes práticas e orientações se dá em decorrência dos conflitos de ideias/perspectivas que permeiam a escola, mas estes conflitos também são produtores desta construção curricular, assim como o tempo, que se apresenta como elemento significativo neste processo.

Palavras-chave: Educação física escolar. Ensino fundamental. Construção curricular

Returns, contours and deviations: Physical Education in the curricular construction of

1 Doutoranda em Ciências do Movimento Humano na Universidade Federal do Rio Grande do Sul (UFRGS). Porto Alegre/Rio Grande do Sul, Brasil. E-mail: natacha_760@hotmail.com

2 Doutorado em Ciências do Movimento Humano Universidade Federal do Rio Grande do Sul (UFRGS). Porto Alegre/Rio Grande do Sul, Brasil. E-mail: elisandro.wittizorecki@gmail.com

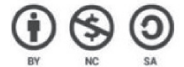

Este texto está publicado sob uma licenca Creative Commons Atribuição NãoComercial-Compartilhalgual - CC BY NC AS Mais detalhes em: https://br.creativecommons.org/licencas/ 
the final years of elementary school in a state school in Rio Grande do Sul

\begin{abstract}
This text is the result of a dissertation and seeks to communicate the findings related to the following specific objectives: a) understand that knowledge is part of Physical Education $(\mathrm{EFI})$ in the final years of elementary school and what places it occupies in curricular construction; b) understand the tensions involved in the school and EFI curriculum building process. The curricular construction of the school and EFI is constituted by movements of return, contour and deviation. The knowledges that integrate this construction are of two orders, of personal formation and of academic formation, and are developed through traditional practices / reproducers, but also through practices that break this logic. This concomitant presence of different practices and orientations occurs due to conflicts of ideas / perspectives that permeate the school, but these conflicts are also producers of this curricular construction, as well as the time, which presents itself as a significant element in this process.
\end{abstract}

Keywords: Physical education at school. elementary school. Curricular construction

Retornos, contornos y desvíos: la Educación Física en la construcción curricular de los años finales de la enseñanza fundamental en una escuela estadual de Rio Grande do Sul

\title{
RESUMEN
}

Este texto surge de una disertación y busca comunicar los hallazgos referentes a los siguientes objetivos: a) comprender que saberes integran la Educación Física (EFI) en los años finales de la enseñanza fundamental y qué lugares ocupa en la construcción curricular; b) comprender las tensiones involucradas en el proceso de construcción curricular de la escuela y de la EFI. La construcción curricular de la escuela y de la EFI está constituida por movimientos de retorno, contorno y desvío. Los saberes que integran esta construcción son de dos órdenes, de formación personal y académica, y se desarrollan través de prácticas tradicionales/reproductoras, pero también de prácticas que rompen esa lógica. Esta presencia de diferentes prácticas y orientaciones ocurre como consecuencia de los conflictos de ideas que permean la escuela, pero estos conflictos también son productores de esta construcción, como el tiempo, que se presenta como elemento significativo en este proceso.

Palabras-clave: Educación física en la escuela. Enseñanza fundamental. Construcción curricular 


\section{QUESTÕES INICIAIS}

O presente texto é fruto de um estudo de mestrado cujo objetivo geral foi compreender como a Educação Física vem se configurando e que lugares ocupa na construção curricular dos anos finais do Ensino Fundamental em uma escola estadual do Rio Grande do Sul em Viamão. Este artigo tem como foco comunicar e discutir os achados da pesquisa referentes aos seguintes objetivos específicos: a) que saberes integram a Educação Física (EFI) nos anos finais do ensino fundamental e que lugares ela ocupa na construção curricular; b) compreender as tensões e problemáticas envolvidas no processo de construção curricular da escola e da EFI.

Para compreender e refletir sobre a temática do currículo, partimos do entendimento de currículo para além da grade de disciplinas ofertadas no universo escolar. Apoiamo-nos em Goodson (2012) ao expressar que o processo de construção de um currículo não é lógico, mas social e político; é a composição de conhecimentos considerados socialmente válidos. Assim como Goodson (2012) e Sacristán (2000), entendemos a construção curricular como a seleção - não neutra - de saberes e conteúdos, mas não apenas isso; entendemos como construção curricular as práticas pedagógicas, os rituais, as normas e os elementos culturais que vão se construindo no cotidiano da escola. Neste sentido, a construção curricular trata do currículo construído a partir das propostas curriculares oficiais, do currículo escrito e do currículo vivido na rotina escolar, ou seja, a construção curricular é tudo que acontece no processo de escolarização (NUNES; RÚBIO, 2008; NERY, 2009).

Diferentes práticas sociais e culturais, em distintos momentos históricos, produziram diferentes significados para a Educação Física escolar. Para Soares et al (1992), a Educação Física é "[...] uma disciplina que trata, pedagogicamente, na escola, do conhecimento de uma área denominada aqui de cultura corporal. [...] O estudo desse conhecimento visa apreender a expressão corporal como linguagem" (SOARES et al., 1992, p.41). Para Darido e Rangel (2005), a Educação Física escolar pode ser um dispositivo de aprimoramento pessoal se levar os estudantes a conhecer, valorizar, apreciar, desfrutar e refletir criticamente sobre a cultura, a saúde e o lazer através de conteúdos como jogos, danças, esportes, lutas e ginástica.

Oficialmente, em nível nacional, os Parâmetros Curriculares Nacionais (1997) sugerem que a Educação Física no Ensino Fundamental siga os princípios de diversidade e inclusão através da cultura corporal de movimento. Propõem alguns objetivos para a Educação Física escolar com preocupação na formação de sujeitos críticos, focando nas possibilidades desta disciplina no ambiente escolar e promovendo o princípio da inclusão por meio de vivências que problematizem criticamente os conteúdos da cultura corporal. É possível perceber que muitas são as motivações, inspirações e formas pelas quais os conteúdos e saberes para as aulas de Educação Física são selecionados. Alguns elementos parecem ser mais definitivos e/ou mais influentes na construção curricular da EFI, como as experiências vividas por docentes durante a Educação Básica; as experiências e saberes construídos na formação inicial dos docentes; as representações e expectativas sobre a docência e sobre a EFI; as possibilidades e experiências de formação continuada e as 
condições estruturais, materiais e políticas do ambiente escolar. Deste modo, a partir e apesar da amplitude de saberes e conteúdos possíveis para as aulas de Educação Física, as decisões e seleções por este ou aquele conteúdo, "quando" e "como" desenvolvê-lo, passam por diversos elementos e questões.

A partir disso, é possível entender que são muitos os objetivos e finalidades atribuídas a Educação Física escolar em razão dos diferentes momentos históricos que atravessaram os sentidos e as práticas deste componente curricular. Todavia, entendemos que sendo a Educação Física componente curricular da Educação Básica, fazendo, assim, parte da escola, há que se pensar qual a finalidade desta disciplina no currículo, o que lhe cabe a partir dos objetivos propostos e estabelecidos na construção curricular da escola.

Apesar de não haver um consenso sobre as finalidades desta instituição, que vem se modificando ao longo de gerações para atender a diferentes propostas de formação de sujeitos, a partir da construção do Projeto Político Pedagógico (pautado nas orientações de diretrizes nacionais e referenciais estaduais e municipais) os professores e a comunidade escolar pactuam e acordam um projeto de formação para sua escola. Assim, consideramos que a Educação Física também precisa fazer parte e se comprometer com este pacto e com estes acordos.

\section{Caminhos metodológicos}

A pesquisa esteve apoiada nos métodos qualitativos, os quais não apresentam a preocupação de generalizar os achados e sim de estudar um grupo ou situação em específico (NEGRINE, 2010, p.61). Além disso, a pesquisa qualitativa ocorre na partilha e no contato com pessoas, fatos, fenômenos e lugares.

A pesquisa foi realizada em uma escola estadual do Rio Grande do Sul localizada em Viamão (a partir de autorização consentida), por meio de um estudo de caso etnográfico, pois, segundo Lüdke e André (1986), o estudo de caso busca retratar e compreender uma realidade singular em sua completude e de forma aprofundada. Yin (2010) sugere que o estudo de caso é realizado quando o intuito é compreender fenômenos contemporâneos e atuais; quando as perguntas orientadoras da pesquisa são "COMO" e "POR QUE"; quando o pesquisador tem pouco ou nenhum controle sobre o fenômeno e quando se propõe estudar um fenômeno em seu meio. Lüdke e André (1986) sugerem que neste tipo de estudo o pesquisador precisará "observar momentos de aula, de reuniões, de merendas, de entrada e saída dos alunos, bem como coletar dados do começo ao fim do semestre/ano letivo" (p.19), pois, como apontam Bogdan e Biklen (1994, p.89), "o estudo de caso consiste na observação detalhada de um contexto [...]". Como expõem Schmidt e Garcia (2001), o estudo etnográfico apresenta características que favorecem a compreensão sobre a cultura escolar, elemento este que tem relação direta com a construção curricular nas escolas.

A escola Múltipla (como foi nomeada pelos participantes e colaboradores da pesquisa) está situada em um bairro pertencente à cidade de Viamão, quinto município da região metropolitana de Porto Alegre no estado do Rio Grande do Sul (REHBEIN; FUJIMOTO, 
2007). Por muito tempo Viamão foi considerada cidade-dormitório, pois grande parte da população trabalhadora da cidade se deslocava para a capital para se empregar e, além disso, poucos espaços de lazer e diversão eram oferecidos na cidade. Este cenário vem se modificando timidamente nos últimos anos (2014-2016), quando parece ter havido um maior investimento nos setores de cultura, lazer e educação da cidade. A título de exemplo, sinalizamos o aumento da oferta de cursos técnicos e superiores, o aumento de estabelecimentos como lancherias e bares e a ampliação de projetos e atividades oferecidas pela prefeitura como cursos de teatro e oficinas artísticas.

Em relação à extensão territorial, predomina no município a área rural, embora sua área urbana seja bastante populosa. A população da cidade é bastante variada quanto ao poder aquisitivo, mas, ainda assim, sua maior parte apresenta renda de até 2 salários mínimos. Nos trechos de Lindemayer (2013) é possível identificar algumas características da cidade

Apresenta uma mistura de cavalos, gaúchos a caráter com condomínios luxuosos e carros importados. A cidade está na história do Rio Grande do Sul desde 1700. Ocupada por índios, tropeiros, portugueses e negros. Com o rápido aumento populacional a cidade ficou precária em muitos aspectos como saneamento, segurança, saúde e lazer (p.10).

As escolas municipais, em sua maioria, ofertam o ensino de $1^{\circ}$ a $5^{\circ}$ ano. A escolarização dos anos finais do Ensino Fundamental e do Ensino Médio fica, em grande parte, sob a responsabilidade das escolas estaduais localizadas no município. Estas costumam estar centralizadas a fim de serem acessíveis para estudantes de diferentes bairros da cidade, diferentemente da escola Múltipla, que se encontra mais perifericamente na cidade e tem como coletivo discente principalmente os moradores de sua redondeza (característica mais comum de se identificar nas escolas municipais).

A escola Múltipla compreende, então, o contexto municipal e local no qual está situada, mas também o contexto estadual de ensino, uma vez que se trata de uma escola estadual. Conforme expressam os dados apresentados pela Secretaria da Educação do Estado do Rio Grande do Sul (RIO GRANDE DO SUL, 2013), por volta de $60 \%$ da população matriculada no estado se encontra no Ensino Fundamental.

Em razão do tipo de estudo e da problemática que o orienta, a pesquisa contou com a observação participante, tendo seu registro em diário de campo (TRIVIÑOS, 1987; MINAYO, 2010) como principal estratégia para recolha das informações. As observações foram realizadas durante o ano de 2016 e tiveram duração de dez meses, iniciando no mês de março e finalizando no mês de dezembro. No diário de campo foram registradas observações de aulas, reuniões, recreios, entradas, saídas, eventos, conselhos de classe e até mesmo de postagens na página do Facebook da escola.

Além das observações, a pesquisa também contou com análise de documentos. Os documentos analisados foram aqueles disponibilizados pelos colaboradores/participantes da pesquisa, como o Regimento Escolar (construído ao final de 2016); o Projeto Político Pedagógico da escola, que se encontra desatualizado (conforme apontamento feito pelos 
colaboradores), sendo sua última versão do ano de 2013; o documento de Reestruturação Curricular Ensino Fundamental e Médio (produzido e enviado para a escola pela secretaria de educação do estado do Rio Grande do Sul); a Planilha de Acompanhamento do Desempenho Escolar da Educação Física; o Calendário Escolar e o Plano de Trabalho da Educação Física. A análise documental foi utilizada como apoio às observações, como propõe Woods (1995).

Foram realizadas entrevistas semiestruturadas com a diretora da escola (Madalena), a supervisora dos anos finais (Pequena) e a professora de Educação Física responsável pelos anos finais do Ensino Fundamental (Janaína) (NEGRINE, 2010).

Com o objetivo de identificar e compreender alguns entendimentos de Educação Física, seus saberes e configurações nas perspectivas do grupo discente da escola utilizamos, também, a técnica do Grupo de Discussão (GD). Foram organizados dois Grupos de Discussão, um com estudantes dos $6^{\circ} \mathrm{s}$ e $7^{\circ} \mathrm{s}$ anos e outro com estudantes dos $8^{\circ} \mathrm{s}$ e $9^{\circ} \mathrm{s}$ anos. Os GD's foram realizados conforme disponibilidade da escola e dos estudantes. No total participaram do GD 13 estudantes do $6^{\circ}$ ao $9^{\circ}$ ano. O GD tenciona apreender um discurso cotidiano sobre uma determinada realidade social (SANTOS, 2007).

A escolha destes diferentes instrumentos de coleta das informações está pautada primeiramente na natureza do estudo, mas também por entender que a variedade destes instrumentos pode oferecer informações significativas e vastas acerca do tema e do campo de investigação. Sinalizamos que, visando atender às questões éticas da pesquisa, os discentes que participaram do Grupo de Discussão assinaram o Termo de Consentimento Livre e Esclarecido juntamente com seus responsáveis, assim como as participantes que realizaram as entrevistas assinaram o termo de consentimento livre e esclarecido. Após transcrição Ihes foi devolvida a entrevista/GD para validação. Ademais, os nomes dos sujeitos foram substituídos por nomes fictícios escolhidos por eles próprios.

\section{Análise e discussão}

A análise permitiu compreender que a construção curricular da escola se configura por diferentes movimentos, sendo eles nomeados de retornos, contornos e desvios. A EFI, nos anos finais do Ensino Fundamental, parece estar integrada à construção curricular da escola na medida em que também compreende esses movimentos.

Alguns movimentos, ações e estratégias presentes na construção curricular remontam a propostas e modelos de outras épocas. Assim, a ideia de "retorno" é utilizada para ilustrar práticas e significados que de certa forma remetem a propostas curriculares de ensino de outros momentos históricos. Neste movimento uma noção a ser destacada é a de eco, algo que se iniciou em um tempo passado, mas ainda repercute atualmente, algo que se repete. Eco é a "repetição de um som devido à reflexão das ondas sonoras. som repetido. fig. memória, rastro, vestígio" (HOUAISS, 2009). Aqui o movimento de retorno é entendido como propostas, práticas, discursos e referências que ainda ecoam no momento atual, dando sentido à escola e às disciplinas escolares, fazendo parte, assim, da construção 
curricular. A supervisora Pequena, por exemplo, indica na sua fala a presença do eco no ensino fundamental ao falar sobre as propostas e metodologias.

“porque assim, esses conteúdos, essas metodologias e formas de avaliação que tão aí pro Ensino Fundamental já estão obsoletos" (Pequena, entrevista).

Foi possível compreender que uma das finalidades atribuídas pelos sujeitos à escola é de formação para vida. Entendemos que em alguns momentos esta formação para a vida é conduzida por um movimento de retorno, pois sofre ecos de perspectivas mais conservadoras de ensino, como práticas disciplinadoras e reprodutoras. Há momentos em que existe uma grande preocupação com a ordem e com a disciplina, um foco na assimilação e socialização de determinadas regras e normas de convivência e comportamento.

"é triste pensar isso, mas a gente precisa, a escola precisa de disciplina [...] educar primeiro e ensinar depois" (Madalena, Diário de Campo, 20.07.2016).

Nesta fala da diretora Madalena podemos captar a presença desses ecos na construção curricular da escola. Ao mesmo tempo, a fala de Madalena também indica uma outra finalidade para a escola, além da formação para a vida (que seria o "educar"), o "ensinar", que remete à aprendizagem de conteúdos, conhecimentos científicos/técnicos. Esse "ensinar" também carrega consigo, nesta construção curricular, alguns ecos.

"Joana pede que os estudantes deem sugestões para as aulas para o ano que vem,
os estudantes sugerem que as aulas sejam mais diferentes, diferente de copiar do
quadro e 'fazer folhinha'" (Diário de campo, 02.12.2016).
"Ai, os professores passam muita coisa no quadro [...] eles acham que a gente vai
aprender uma coisa, assim, rápido e só de copiar do quadro (Jéssica) [...] é e eles
podiam fazer coisas mais diferentes (Clotilde)" (Grupo de discussão, $6^{\circ} \mathrm{S}$ e $7^{\circ} \mathrm{s}$ anos).
"Ah sora, aqui só tem aula, aula, aula [...] assim, de copiar do quadro, de escrever,
não tem muita coisa diferente (Júlia) [...] até tem o Café com leitura (Alisson)[...] mas
é uma vez por trimestre (Romerito)" (Grupo de discussão, $8^{\circ}$ S e e $9^{\circ} \mathrm{S}$ anos).

A EFI, nessa mesma esteira, também parece ser constituída por ecos, tendo em vista que algumas de suas propostas nesta escola conectam-se com modelos e paradigmas de EFI de outros momentos históricos aproximando-se do que indica Ilha (2015) ao dizer que "diferentes discursos, como os ligados ao militarismo, esportivismo, higienismo atravessaram, e alguns ainda atravessam, as práticas da Educação Física nos processos de ensino desta disciplina no currículo escolar" (p.16). Nesse sentido, a organização apresentada por Janaína parece sofrer ecos do "paradigma da aptidão física e esportiva" (BRACHT, 1999), em que havia ênfase no desenvolvimento da aptidão física e no desenvolvimento do desporto. Apresentamos abaixo trecho do diário de campo que ilustra essa questão.

"ela explica que ainda está planejando, mas que por enquanto ela vem organizando da seguinte forma: $6^{\circ}$ anos, $1^{\circ}$ e $2^{\circ}$ trimestre (coordenação motora, reflexo e atividades lúdicas), $3^{\circ}$ trimestre (maior foco nos esportes -1 aula prática e 1 teórica); 
$7^{\circ}$ anos, Resistência física; $8^{\circ}$ e $9^{\circ}$, Frequência cardíaca, circuito, conhecimento sobre o corpo" (Diário de campo, 28.03.2016).

Da mesma forma, nos itens que integram a Planilha de Acompanhamento do Desempenho Escolar de uma turma do $6^{\circ}$ ano é possível identificar elementos relacionados às perspectivas citadas acima e também elementos que se relacionam com uma prática educativa mais conservadora.

"comportamento, uso de roupa adequada, avaliação cardiorespiratória" (Planilha de Acompanhamento do Desempenho Escolar).

As aulas de Educação Física são realizadas de duas formas, de forma dirigida e de forma "livre". Nas aulas dirigidas Janaína costuma trabalhar com fundamentos dos esportes, habilidades motoras e exercícios de condicionamento físico. A metodologia das aulas é comumente por meio de atividades analíticas e técnicas, mas em alguns momentos a professora insere outras atividades mais globais. Entendo que nas aulas dirigidas predominam os ecos da esportivização e da aptidão física.

Ao mesmo tempo, pude identificar que em meio ao movimento de retorno também ocorrem alguns contornos e desvios; ou seja, frente a situações que parecem caminhar em um determinado sentido existem, e/ou se criam, possibilidades para contorná-las ou desviar seu rumo. Dessa forma, convém considerar que a construção curricular não se constitui como um caminho único, uniforme, retilíneo e com um ponto de chegada claro, definitivo, fixo e determinado.

Assim, a inovação e as práticas mais centradas na construção da autonomia parecem se configurar como movimentos de contorno e desvio dentro da construção curricular. A possibilidade de os estudantes construírem e exercitarem a autonomia, criarem e reinventarem por meio de uma prática cooperativa pode ser uma forma de contornar ou desviar de práticas e modelos de ensino que estão estabelecidos na cultura da escola e que ainda ecoam no seu cotidiano.

\footnotetext{
"Ahh, tem a gincana, a festa junina, o teatro, são coisas que outras escolas não têm e aí é diferente, não é só de copiar (Lucka) [...] tem a mostra de ciências, o Natal (Coraline)[...] tem a horta (Don Juan)[...] ahh, o café com leitura (Coraline)[...] a gente apresenta, é diferente das aulas normais" (Grupo de discussão, $8^{\circ} \mathrm{s}$ e $9^{\circ} \mathrm{s}$, 30.09.2016).

"A escola tem o que eu vejo aqui o lado humano junto, mas também o lado inovador, a escola tenta sempre com os projetos inovar, sempre desafiar, sempre trabalhar diferente, apesar de ter algumas coisas que a gente é extremamente tradicional, mas eu vejo que ela possibilita que os alunos tenham outras vivências" (Madalena, entrevista).
}

A EFI, nesse sentido, também parece comportar esses contornos e desvios em sua construção. Nas aulas ditas "livres" se percebe um movimento maior de desvio das práticas disciplinadoras, centradas no professor ou mesmo esportivistas. Nestas aulas parece ganhar 
espaço a criação, a produção dos estudantes através do chamado "esporte da escola" (VAGO, 1996), na medida em que os estudantes reelaboram/reconstroem jogos e práticas a partir de suas necessidades, interesses e possibilidades. Ao centrar-se na autonomia dos estudantes, na socialização, na coletividade e na preocupação com seus desejos e com um olhar para suas necessidades e individualidades a EFI parece harmonizar mais com um discurso progressista acerca da $\mathrm{EFI}$, desviando de uma prática mais disciplinadora, esportivista e biologicista (BRACHT, 1999).

“Quando é livre a gente joga [...] ahh, não é o três corta certinho, é o três corta que a gente inventa" (Jéssica, Grupo de discussão $6^{\circ} \mathrm{s}$ e $7^{\circ} \mathrm{s}, 12.12 .2016$ ).

"Na quadra principal jogam futebol meninos das duas turmas. Na quadra secundária jogam futebol 4 meninos e 2 meninas. No pátio alguns alunos da 72 jogam três corta. Eles jogam com regras próprias (no três corta por exemplo não vale fazer panelinha; vale segurar a bola; no futebol jogam com apenas um goleiro, a bola não sai de jogo, o que é ou não falta é decidido pelo coletivo)" (Diário de campo, 22.08.2016).

Esclarecemos que não pretendemos aqui defender ou enaltecer "as aulas livres". Nosso olhar para as aulas livres foi no intento de compreender o que ali acontecia e o que se produzia. Nesse sentido, cabe destacar que apesar dessa possibilidade de desvio de uma prática disciplinadora e regrada para uma prática de criação e autonomia, algumas coisas merecem ser tensionadas nas aulas livres. Uma dessas seria de problematizar primeiramente a própria nomenclatura atribuída a esse tipo de aula, "aula livre". Seria possível haver uma "aula" realmente "livre"?

"Aula" e "livre" parecem ser elementos de difícil articulação. O momento de aula é entendido como a relação de troca de aprendizagem, ou como momento de ensinamento entre mestre e aprendiz, um momento de interação entre professor e aluno (TARDIF; LESSARD, 2008). Já o termo "livre", conforme o dicionário Houaiss (2009), significa "que é senhor de si e de suas ações; que não está sob o jugo, que não é escravo de outrem; que não é prisioneiro; que goza de liberdade física; que foi absolvido; isento de restrições, controle ou limitações; que não sofre a influência de grupos de interesse". Bem, a partir dessa definição se poderia refletir sobre a possibilidade de haver algo que realmente se configure como "livre" em nossa sociedade, mas para esse momento iremos nos ater a reflexão sobre a possibilidade de haver uma "aula" que seja "livre". Como vimos pela definição do termo, "livre" tem a ver com liberdade física, com ser senhor de si e de suas ações, com estar isento de restrições, controle, limitações ou influências.

Nas aulas nomeadas de "aulas livres" tais condições não estavam presentes, aos estudantes são apresentados limites que devem ser respeitados dentro deste momento de aula. Além das regras claramente estabelecidas, como não namorar, não fumar, não beber (que são as normas gerais da escola) existem outros limitadores, que parecem determinar quais práticas ou atitudes os estudantes podem ter naquele momento, como as práticas e jogos que realizam. As representações e significações que os estudantes vão construindo em relação às práticas corporais e às questões de gênero, por exemplo, parecem intervir 
nas dinâmicas e práticas que se desenvolvem no interior das aulas de EFI. Nas aulas livres, é possível notá-las por meio da ocupação do espaço e da escolha das práticas, que também são reforçadas pelos enunciados dos estudantes.

\footnotetext{
“os guris pegam a bola e vão pra quadra (Clotilde) eles sempre vão querer jogar futebol e as gurias sempre vão querer ficar sentadas (Jéssica) mas e os guris jogam o quê? Peteca ? (Jorge)" (GD, $6^{\circ}$ s e $7^{\circ}$ s).

"Na aula de EFI alguns meninos e uma menina jogam futebol. Outros grupos de meninas ficam espalhados pela arquibancada" (Diário de campo, 14.03.2016).
}

Por conta desses atravessamentos com as diferentes representações e entendimentos que as pessoas vão construindo em relação aos saberes, às práticas e ao comportamento, alguns procedimentos realizados e vivenciados na Educação Física acabam conformando e se identificando com uma determinada "cultura da Educação Física". Essa cultura não é homogênea, mas permeia as representações e significações que circulam acerca da EFI e dos seus saberes. A supremacia do esporte como conteúdo central das aulas também ganha significância nesse contexto.

“ [...] fazer qualquer outra atividade que represente a Educação Física que não seja esporte é difícil, incomoda um pouco tirar isso [...]" (Janaína, entrevista).

"as aulas de EFI são pra gente aprender os esportes, pra gente poder jogar no JIMV" (James, G.D., $8^{\circ}$ s e $9^{\circ}$ s).

Essa presença do esporte como conteúdo hegemônico nas aulas de EFI ou mesmo como sinônimo de EFI corrobora com o que aponta Ilha (2015) ao dizer que esta centralidade do esporte nas aulas permitiu um discurso de que "Educação Física é esporte" (p.73). Os estudantes até expressam o desejo de aprender outras coisas, mas não consideram que isso possa fazer parte das aulas. No grupo de discussão foi citado, por exemplo, o Taekwondo, e quando lhes perguntei por que não pediam para a professora, já que dizem ter uma boa relação com ela, eles dizem não fazer parte, como se outros saberes além do esporte não pudessem pertencer às aulas de EFI.

Neste sentido, este espaço-tempo comumente nomeado de "aula livre" parece estar bastante distante de uma prática de liberdade, estando muito mais próximo de um espaço-tempo negociado, assim como também acontece em outras disciplinas, como foi possível identificar ao longo das observações. Assim sendo, caberia rever a forma como esse espaço-tempo vem sendo nomeado e pensado.

Isto posto, entendemos que tanto a construção curricular da escola Múltipla, quanto a EFI inserida nesta escola, cumprem simultaneamente dois papéis, de reprodução/transmissão de saberes acumulados e de produção cultural; e, da mesma forma, acontecem através de duas principais perspectivas, uma perspectiva mais reflexiva/autônoma/criativa

3 Jogos Interescolares do Município de Viamão 
e outra mais tradicional e disciplinar. Compreendemos que alguns elementos podem ser significativos para essa configuração, o tempo e o conflito.

O tempo se relaciona com a construção curricular principalmente quando pensamos/olhamos para a concretização (ou não) de uma proposta curricular. Mesmo quando uma proposta em implementação logra aderência do coletivo docente sua efetivação não tem garantia. As falas a seguir destacam o entendimento de que uma proposta demora a ser recebida, analisada e apreendida para então ser efetivada (afora as questões estruturais e de investimento que devem ser observadas):

\footnotetext{
"daí esse ano que a gente tava começando a colher os frutos aí muda tudo de novo, porque uma proposta não pode ser de 5 anos, tem que ser de 10 pra mais pra gente sentir o efeito" (Pequena, entrevista).

"quando tu tá começando a assimilar uma proposta daí muda, cada governo que entra vem com uma proposta nova. E eu acho que não é de um ano pro outro que tu vai ter e vai ver resultado do processo. Não sei quantos anos vai ter resultado, mas tem que ser um crescente" (Madalena, entrevista).
}

Esse entendimento se aproxima das colocações apresentadas por Hargreaves (1995) ao tratar do tempo na implementação curricular. Para Hargreaves (1995),

[...] no contexto de inovação os professores sentem pressão e ansiedade em função das excessivas exigências temporais, além da culpabilização e da frustração por implementarem um novo programa com maior lentidão e menor eficácia do que as requeridas pelos cronogramas administrativos [...] Neste caso, parece que o administrador se mostra insensível diante da perspectiva temporal subjetiva do professor e das condições de trabalho nas quais se funda ${ }^{4}$ (p. 126).

Nesse sentido, entendemos que o tempo é um elemento que pesa significativamente para que a construção curricular da escola Múltipla, e da EFI neste contexto, seja permeada por diferentes práticas, sentidos e perspectivas. Assim, a construção curricular parece estar sempre em transição, pois não há um rompimento com uma perspectiva para que outra possa assumir o seu lugar e, desta forma, ambas vão convivendo nesta construção.

Todavia, esse convívio não é necessariamente harmonioso, mas sim repleto de conflitos. Além do tempo, o conflito de ideias e perspectivas também pode ser uma razão possível para a não concretização de uma nova proposta.

No ano de 2016 iniciou-se no estado do Rio Grande do Sul uma Reestruturação Curricular para o Ensino Fundamental e Médio. Dentre as demandas e mudanças dessa reestruturação a 28 $8^{\mathrm{a}}$ CRE (Coordenadoria Regional de Educação) buscou padronizar o uso da nota como expressão da avaliação nas escolas. Essa mudança, no entanto, entrou em conflito com a perspectiva da escola Múltipla, que historicamente trabalhava com a avaliação por meio de conceito.

4 Tradução feita pelos autores. 
“o que é mais difícil dessa reforma, o que mais bate de frente é a questão da nota, porque aqui na escola sempre foi por conceito" (Pequena, entrevista).

Diante dessa questão a escola empreendeu um dialogo com a Coordenadoria na tentativa de empregar resistência a essa mudança, evidenciando que existem possibilidades de se resistir, contornar ou desviar de práticas das quais de discorda. Assim, Apesar de haver certo controle das práticas realizadas nas escolas, professores e alunos ainda conseguem transformar algumas agendas para atender os fins que lhes interessam (APPLE, 1997). Em alguns momentos essa resistência será mais direta, mais explícita, empregada frente a alguma decisão ou ação; em outros momentos a resistência aparece de forma mais sutil, mais interna, através de movimentos de contra conduta. A contra conduta seria uma espécie de resistência às mais variadas formas de subjetivação das quais se discorde (LOPES; MORGENSTERN, 2014). Nesse sentido, a não concretização/efetivação de uma proposta pode se configurar como uma contra conduta ocasionada por um conflito de perspectivas entre os gestores da proposta e o coletivo da escola. A partir disso, é possível que a escola e a EFI, ao não efetivarem a materialização de uma proposta, estejam empregando resistência, criando possibilidades para contornar as demandas colocadas, mas também é possível que o tempo para a efetivação dessa proposta não tenha sido o tempo necessário.

O conflito, no entanto, não se faz presente apenas na relação entre gestores e comunidade escolar, mas na relação entre os próprios sujeitos da escola.

"Por que o formato e o jeito que a gente pensa que deve ser o ensino não é comum entre todos os professores" (Madalena, Diário de campo, 20.10.2016).

Ainda, nos referimos ao conflito não apenas como disputa entre pessoas, mas também como um dilema, pois foi possível observar que uma mesma pessoa se posicionou ou agiu de formas diferentes (incoerente, contraditória) frente a situações semelhantes, ou mesmo apresentou dúvidas ao se posicionar sobre alguma problemática. Este conflito/ dilema corrobora com o que sinaliza Apple (1997) ao destacar que

as pessoas podem manter posições simultaneamente progressistas e democráticas [...] Não apenas existem tensões no interior destes grupos e entre eles, mas os indivíduos são, também, eles mesmos, internamente contraditórios [...] haverá elementos de "bom senso" e "mau senso" em nossas complexas experiências ideológicas (p.21).

Neste sentido, o conflito parece permear o coletivo da escola, tanto por parte dos docentes quanto dos discentes. Os discentes, por vezes, atribuem à escola uma finalidade de oferecer uma formação que Ihes permita "serem pessoas melhores" (Jéssica, Grupo de discussão $6^{\circ}$ e $7^{\circ}$ ), mas agem, muitas vezes, como se a escola não fosse importante.

"eu venho porque sou obrigada [...] não é lei não, é a minha mãe mesmo que me obriga" (Jéssica, Grupo de discussão, $6^{\circ}$ s e $7^{\circ}$ s anos). 
Também parecem confusos acerca do que esperam da escola, dizem que a escola é "muito puxada", mas também dizem que se for muito fácil não prepara para a vida, reclamam que os professores dão muitos trabalhos, mas também não gostam de ficar ociosos. Em relação às aulas de Educação Física, por exemplo, solicitam constantemente "aula livre" e/ou precisam ser convencidos a participar, mas também sugerem que os que não participam façam trabalhos escritos para compensar (Grupo de discussão, $6^{\circ} \mathrm{S}$ e $7^{\circ} \mathrm{S}$ anos). A professora Janaína também destaca esse conflito ao falar sobre a dificuldade de agradar os estudantes, pois

“um dia tu dá aula e eles te enchem o saco pra tu largar a bola aí tu larga a bola e eles dizem que tu não dá aula... é muito difícil trabalhar com adolescente, eles não sabem o que eles querem" (Janaína, entrevista).

Os professores, da mesma forma, por vezes adotam posturas mais conservadoras e autoritárias e em outros momentos são mais inovadores e críticos. Além das ações também é possível identificar estes conflitos e dilemas nas dúvidas e problemáticas que os docentes apresentam. Nas falas de Janaína, a seguir, é possível identificar esse dilema, pois ao mesmo tempo em que destaca uma preocupação com o individual, com a situação e a singularidade de cada aluno também indica uma necessidade de aquisição de algumas aprendizagens mínimas e uma certa lógica meritocrática.

\begin{abstract}
"A Educação Física tem que ser uma coisa pra passar, pra fazer o aluno gostar daqui, aprender a se cuidar, saber o quanto aquilo é importante pra vida dele [...]Então eu tento ter esse olhar de professora, de ser humano, mais individual. Não só focando nos problemas, nas dificuldades que cada uma tem, mas focando naquele indivíduo, no momento que ele ta passando[...]" (Janaína, entrevista)

"Janaína fala que acha que a questão da avaliação é confusa porque quando se retém o aluno não se dá motivação, acaba-se prejudicando o aluno, mas quando se passa o aluno sem ele ter construído o conhecimento ele também terá dificuldade de acompanhar a turma, além de que os colegas que se dedicaram reclamam e contestam" (Diário de campo em 06.06.2016).
\end{abstract}

Assim, não parece haver uma total concordância ou unidade de pensamento por parte do corpo docente ou discente quanto aos entendimentos acerca da formação ou sobre os meios pelos quais atingir os objetivos estabelecidos. Isso atesta o que afirma Ball (1994) ao dizer que as escolas, como qualquer outra instituição educativa, caracterizam-se por ausência de consenso. Tomamos esses conflitos e dilemas como produtivos e produtores, e não como algo negativo ou prejudicial para a escola e para a formação dos estudantes, pois quais seriam as possibilidades de construção onde só existe concordância? A divergência e os conflitos permitem diferentes rumos e situações, possibilitando que o currículo se constitua mais como experiência do que como certeza. Segundo Ball (1994), não se deve supor que o conflito é sempre destrutivo, o conflito "pode ser, e com frequência é, muito saudável; ou pode revitalizar um sistema que, do contrário, se estancaria" (p.36). Isto posto, compreendemos que esses dilemas e conflitos permitem que a escola e o coletivo 
docente se repensem e construam novos caminhos e metas. Parece, neste sentido, residir alguma possibilidade/potencialidade na divergência.

A partir do exposto, é possível identificar e compreender alguns movimentos de retorno, de contornos e outros de desvio que integram a construção curricular desta escola e da EFI neste contexto. Compreendemos que estes movimentos se fazem presentes na medida em que a construção curricular é permeada por representações e práticas de ensino e de escola de outras épocas; pelas possibilidades de se contornar ou desviar de propostas e imposições que estejam em desacordo com a perspectiva da escola; pelo fato de professores e gestores acabarem desviando dos objetivos e propostas traçados por eles próprios, ou mesmo por desviarem/contornarem suas próprias premissas anteriormente estabelecidas e se disporem a se repensar, a se refazer.

Esses movimentos têm como aspectos significativos o tempo e o conflito, pois são noções que se relacionam com a produção desses movimentos. Os conflitos os impulsionam, são o tiro de largada, o combustível para que a construção curricular se mantenha em ação. Já o tempo tem conexão com as possibilidades dentro da construção curricular, o tempo que uma proposta leva para ser analisada e compreendida para que então possa ser negada ou incorporada.

\section{CONSIDERAÇÕES FINAIS}

A pesquisa permitiu compreender que a construção curricular é permeada por movimentos de resistência, de adesão, de tentativa e de retrocesso (retornos, contornos e desvios). Entendemos que os conteúdos da escola se encontram centrados naqueles conhecimentos que são entendidos como necessários para que os estudantes realizem as provas de vestibular para ingresso nas universidades, mas os saberes para a vida também integram essa formação. Ainda assim, parece-nos que os conteúdos por si só não determinam o seu uso, sendo a questão metodológica o ponto chave para a associação dos conteúdos com a vida cotidiana, com o mercado de trabalho ou com as avaliações em larga escala para ingresso na vida acadêmica. Neste sentido, as metodologias utilizadas pela escola variam, assim como suas finalidades. Há momentos em que se focaliza em uma metodologia considerada mais inovadora, mais contextualizada, como nas saídas de campo ou nos projetos em que os estudantes realizam trabalhos de pesquisa de forma mais autônoma, momentos que desestruturam a organização da escola, pois se organizam em uma lógica diferente daquelas utilizadas comumente nas salas de aula. Em outros momentos fica mais evidente um trabalho mais tradicional, por meio de textos passados no quadro, da realização de atividades em livros didáticos, atividades de memorização e repetição.

A EFI, a partir das informações analisadas, parece fazer parte desta construção com a finalidade de aquisição de saberes e de maior autonomia e satisfação. Integrada na perspectiva da escola, a EFI também se realiza por meio de diferentes metodologias. Nas aulas dirigidas, como o nome já diz, a ênfase da aula se dá pela condução e organização da professora, em que a mesma estabelece a sequência, o tempo e a dinâmica das 
atividades. As aulas dirigidas ainda são compostas por diferentes metodologias diretivas, algumas atividades são mais analíticas, realizadas por meio de circuitos ou estafetas, e outras são mais globais, por meio de jogos reduzidos ou jogos lúdicos. Nas aulas livres as atividades são organizadas pelos próprios estudantes, tendo algumas vezes a intervenção da professora que faz sugestões e comentários para auxiliar os estudantes. Os conteúdos da $\mathrm{EFI}$, diferentemente dos conteúdos citados anteriormente, não estão relacionados com a vida acadêmica ou com o mundo do trabalho (a não ser para aqueles estudantes que pretendem ser atletas), mas com a vida cotidiana dos estudantes através de saberes considerados importantes para que estes tenham uma vida consciente, ativa e saudável. Isso, no entanto, nem sempre é compreendido pelos estudantes, que muitas vezes não veem sentido nos conteúdos trabalhados.

Mesmo que existam práticas de interdisciplinaridade a escola ainda é predominantemente multidisciplinar e o que caracteriza e permite essa multidisciplinaridade é o fato de as diferentes disciplinas trabalharem em prol da formação dos estudantes, mas cada uma de sua forma e com seus objetivos específicos. Consideramos, assim, que neste contexto cada disciplina tem seu papel, sua função na construção curricular, e seria justamente a composição e a integração dessas diferentes disciplinas, que acontecem de formas diferentes, que têm diferentes objetivos e perspectivas que permitiria à construção curricular não caminhar em um sentido único e estático. Neste sentido, a construção curricular como ela vem sendo (múltipla) só é possível porque as disciplinas e as práticas que a integram não caminham todas num mesmo sentido, a construção curricular é plural, é múltipla, porque é composta de práticas e disciplinas que acontecem de diferentes formas e com diferentes finalidades.

No caso da construção curricular dessa escola, algumas disciplinas vão atender mais às demandas de formação para a atuação profissional futura dos estudantes, outras vão atender às demandas de preparação para ingresso na vida acadêmica, enquanto outras atenderão a demandas mais relacionadas à vida pessoal dos estudantes. Isso não significa que uma mesma disciplina não possa cumprir diferentes papéis e ocupar diferentes lugares nessa construção curricular, pois, dependendo da forma como se organizam e das metodologias utilizadas, podem servir para diferentes objetivos. A questão é que cada disciplina parece ter uma preocupação central nessa construção. A Educação Física, na escola Múltipla, parece ocupar tanto um lugar de formação pessoal, de caráter, de valores, quanto uma formação pessoal de conhecimento de si, do próprio corpo, que permite, de alguma forma, que os estudantes acessem práticas que Ihes proporcionem uma ação autônoma e consciente de atitudes e práticas de lazer e/ou saúde. Esclarecemos, por fim, que dito isso não estamos defendendo que este deva ser sempre o lugar e o papel da EFI na construção curricular de qualquer escola, em qualquer contexto, mas sinalizando que na escola Múltipla é assim que ela se integra à construção curricular. 


\section{REFERÊNCIAS}

APPLE, Michel W. Conhecimento oficial: a educação democrática numa era conservadora. Petrópolis, RJ: Vozes, 1997.

BALL, Stephen J. La micropolítica de la escuela: hacia uma teoria de la organización escolar. Barcelona: Paidós, 1994.

BRACHT, Valter. A constituição das teorias pedagógicas da educação física. Cadernos Cedes, ano XIX, nº 48, Ago, 1999.

BRASIL, Secretaria de Educação Fundamental. Parâmetros curriculares nacionais : Educação Física/Secretaria de Educação Fundamental. — Brasília: MEC/SEF, 1997.96p. Disponível em: < http://portal.mec.gov.br/seb/arquivos/pdf/livro07.pdf>. Acesso em 07 de março de 2015. BODGAN, Robert; BIKLEN, Sari K. Investigação qualitativa em educação: uma introdução à teoria e aos métodos. Porto: Porto Editora, 1994.

DARIDO, Suraya C.; RANGEL, Irene C. Educação Física na escola: implicações para a prática pedagógica. Rio de Janeiro: Guanabara Koogan, 2005.

GOODSON, Ivor F. Currículo: teoria e história. Petrópolis, RJ: Vozes, 2012.

ILHA, Franciele Roos da Silva. A regulação curricular da Educação Física na escola e seus efeitos no trabalho de professores iniciantes. Tese de doutorado, Universidade Federal de Pelotas, 2015.

HARGREAVES, Andy. Profesorado, Cultura y Postmodernidad. Madrid, Morata, 1995.

LINDEMAYER, Cristiane Kroll. Movimentos pela cidade de Viamão/RS. Trabalho de Conclusão de Curso, Especialização em Educação em Saúde Mental, Universidade Federal do Rio Grande do Sul, 2013, 22p.

LOPES, Maura Corsini; MORGENSTERN, Juliane Marshal. Inclusão como matriz de experiência. Pro-Posições, v. 25, n. 2, p. 177-193, maio/ago. 2014.

LÜDKE, Menga; ANDRÉ, Marli. Pesquisa em Educação: Abordagens Qualitativas. São Paulo: EPU, 1986, 99p.

MINAYO, Maria Cecília S. (org.). O desafio do conhecimento: pesquisa qualitativa em saúde. 12 Ed. São Paulo: Hucitec, 2010, 407p.

NEGRINE, Airton. Instrumentos de coleta de informações na pesquisa qualitativa. In: MOLINA NETO, Vicente; TRIVIÑOS, Antonio N. A pesquisa qualitativa na Educação Física: alternativas metodológicas. Porto Alegre: Sulina, p.61-99, 2010.

NERY, Vanderley Elias. Currículo como processo vivenciado na escola. Revista Espaço Acadêmico, 2009. Disponível em: http://www.espacoacademico.com.br/096/96nery. html Acesso em: 29 nov. 2016.

NUNES, Mario Luis Ferrari; RÚBIO, Katia. O(S) Currículo(S) da Educação Física e a Constituição da Identidade de Seus Sujeitos. Currículo sem Fronteiras, v.8, n.2, pp.55-77, 2008.

REHBEIN, Moisés Ortemar; FUJIMOTO, Nina Simone Vilaverde Moura. Análise Ambiental Urbana: Vila Augusta/ Viamão/ RS. BGG n. 33: Porto Alegre, p. 215 - 232, 2007. RIO GRANDE DO SUL. Secretaria de Educação do estado. Departamento de Planejamento. Diagnóstico da Educação Básica do RS, 2013. 
dezembro/2018

SACRISTÁN, J.Gimeno. O currículo: uma reflexão sobre a prática. 3. ed. Porto Alegre: Artmed, 2000.

SANTOS, Marzo Vargas. O estudante negro na cultura estudantil e na educação física escolar. Dissertação (mestrado), Universidade Federal do Rio Grande do Sul, 2007, 240p.

SCHMIDT, Maria Auxiliadora M.Santos; GARCIA, Tania Maria F. Discutindo o currículo "por dentro": contribuições da pesquisa etnográfica. Educar: Curitiba, n. 17, p. 139149. 2001.

SOARES, Carmen L. et al. Metodologia do ensino de Educação Física. São Paulo: Cortez, 1992, 119 p.

TARDIF, Maurice; LESSARD, Claude O Trabalho Docente: elementos para uma teoría da docência como profissão de interações humanas. Petrópolis, Editora Vozes, 2008.

TRIVIÑOS, Antonio N. Introdução à Pesquisa em Ciências Sociais: A Pesquisa Qualitativa em Educação. São Paulo: Editora Atlas, 1987, 175p.

VAGO, Tarcísio Mauro. O "esporte na escola" e o "esporte da escola": da negação radical para uma relação de tensão permanente Um diálogo com Valter Bracht. Movimento, Ano III, n 5, 1996.

WOODS, Peter. La escuela por dentro: la etnografia en la investigacion educativa. Barcelona: Paidos,: Ministerio de Educacion y Ciencia, 1987.reimp. 1995. 220p.

YIN, Robert K. Estudo de caso: planejamento e métodos. 4. ed. Porto Alegre: Bookman, 2010. 248 p.

Recebido em: Novembro/2017

Aprovado em: Fevereiro/2018 